\title{
TEACHING THE VARIETY OF SYNTACTIC STRUCTURES USING ENGLISH LANGUAGE NEWSPAPER HEADLINES
}

\author{
Svetlana Iljina \\ Rezekne Academy of Technologies, Latvia \\ Valentīna Prikule \\ Rezekne Academy of Technologies, Latvia
}

\begin{abstract}
The research examines the variety of syntactic structures that are used in formation of newspaper headlines in British press. The report focuses on the peculiarities of newspaper headlines in terms of their syntactic structure. The present study also points out the influence of the sentence structure on the meaning of the entire headline.
\end{abstract}

Keywords: comprehension, headlinese, interpretation, meaning, syntactic structures, transformation.

\section{Introduction}

In the age of highly developed information technologies and the world communication network, printed mass media have taken a minor role in the people's lives. There are many other numerous sources of information on international, national, and local news available for the mass audience. Unfortunately, the press does not own the domineering position in the readerfriendly layout of printed information. Due to this, editors take pains to attract the readers to new issues of this or that newspaper or magazine. Offering a good deal of solely informative texts and reports, newspapers do not look appealing to the readers these days. Similarly, the present-day information overload distracts the reader's selectivity of news items.

Nevertheless, newspaper language and the language of headlines offer a lot of possibilities to master the English language at an advanced and proficiency level. Linguistic complexity of the language of newspaper headlines encourages learners to explore the language profoundly. In turn, the language instructors at a tertiary level should facilitate the language study in order to pursue the most effective methods and techniques in teaching the language complexities. Students mastering English as a second language encounter numerous problems to render their native language discourse into the foreign language and vice versa. Moreover, learners should be aware of the specific pragmatic functions of particular syntactic structures. Apart from the traditional formal instruction on 
the language use, it is of utmost importance to develop teaching strategies to include language pragmatics into the learning process.

The key issues for the present research are the most frequent problems caused by the syntactic complexity and the absence of the equivalent syntactic constructions in the target language system. The aim of the present research is to define the most problematic constructions for understanding and translating, and develop the techniques that will facilitate the quality of the language learning.

\section{The Background of the Research}

Headlines of newspaper articles serve as a means of navigation through the influx of reports, features, and news covering articles. Bowels and Borden (1997:189) state that headlines act as a summary of the article and tell in short what the story is about (Smith and Michalak, 1978:15). Headlinese, as a special style applied to writing headlines, has already established the theoretical background for further research.

Reah (2002: 13) refers to the headline as a "unique type of text". The language of a headline is restricted in terms of its linguistic devices. Thus, the language of headlines has triggered the development of a certain lexicon and particular syntactic structures. The key function of this kind of language is to attract the readers' attention to the most breaking news and the paper itself. The unique peculiarities of the headlinese provide the reader with the opportunity to skim the headlines and grasp the content of the articles in a more contracted form. To draw the reader's attention to a particular story, the headline should contain stylistically and emotionally coloured words and simplified syntactic structures.

Unfortunately, this tendency has become a major cause for numerous ambiguities on lexical and syntactical levels. Such ambiguities affect the addressee's comprehension and interpretation of the content of an article, which, consequently, may lead to misunderstanding and even a conflict.

In need of additional space for numerous articles and reports, the headline writers adhere to a telegraphic style of writing, which presupposes the omission of words and transformation of standard structures in phrases and sentences.

Newspaper texts serve as a resourceful means of teaching a language with the help of authentic materials to the students majoring in the English language as a foreign language. Newspapers provide a wide range of up-to-date and actual thematic vocabulary.

Headlines have become a challenge for the reader making an attempt to decipher the main idea of the story. Traditionally, most tabloids exploit stylistically marked vocabulary in their headlines in order to attract reader's attention to scoops and sensationalist news. Unfortunately, the choice of words 
for the headline is not always relevant to the real content of the article. The use of puns, wordplay, allusions, and cultural references cause difficulties in correct understanding of the headline meaning and summarising main ideas reported in the article.

Reah (2002: 73) emphasises a fundamental role of syntax in establishing the relationship between linguistic elements in a sentence. As headlines are presented in a form of sentences and expressions, we may discuss how the elements of these sentences or expressions are interrelated. The relationship between the elements will influence the process of establishing the meaning.

\section{The Data Analysis}

The present research is focused on identifying the reasons for misunderstanding and poor comprehension of headlines in British quality press. The learners of advanced language studies majoring in applied translation and communication were given a set number of headlines with possible interpretations. The aim of the research is to identify the most confusing and least understandable construction patterns of headlines due to their structural and syntactical complexity. As many as 100 headlines were given to 20 students to find appropriate interpretation for each headline. The data were processed and analysed.

The results of the examination of the students' comprehension of headline meanings are reflected in Table 1 below.

Table 1 Correlation between Structures and Misunderstandings

\begin{tabular}{|l|l|l|}
\hline Syntactic structures & Number of students & $\begin{array}{l}\text { Percentage of } \\
\text { misunderstandings }\end{array}$ \\
\hline Present Simple & 10 & $50 \%$ \\
\hline Modals & 12 & $60 \%$ \\
\hline Participles & 15 & $75 \%$ \\
\hline Class shift & 17 & $85 \%$ \\
\hline Complex structures & 14 & $70 \%$ \\
\hline
\end{tabular}

Due to numerous causes for misunderstanding of the content of the headline, the techniques of explanation of the structural peculiarities on linguistic and pragmatic basis are required for the language study course. Thus, the research offers possible ways how to clarify the structural complexities found in the selected newspaper headlines. 


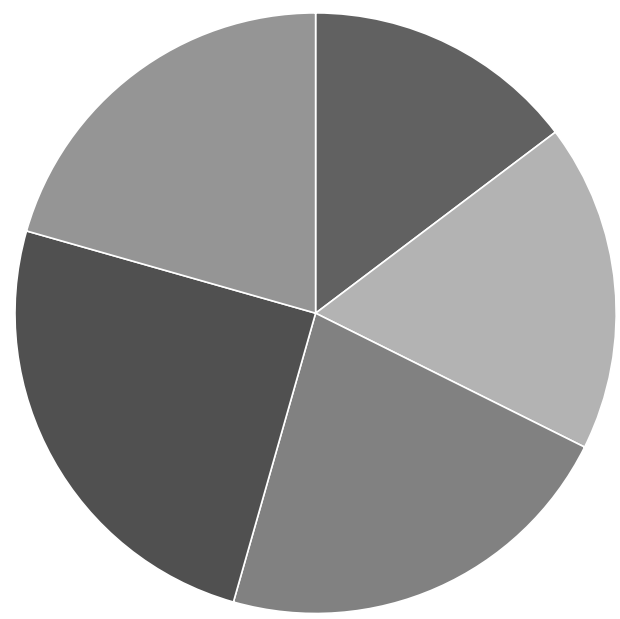

- Present Simple

Modals

- Participles

- Class shift

- Complex structures

Figure 1 Variability of syntactic structures involved in headline misunderstanding

According to the data received during the research, we conclude that the most complicated constructions are class-shifts (See Figure 1). The author operates with different word classes that disturb the reader's understanding of the main idea. Due to the flexibility in word class transformation and polysemy of English nouns and verbs, the most semantically confusing word classes are noun-verb class-shifts.

\section{(1) Mid-concert selfie stage invasions - hasn't Dvorák suffered enough?}

Headlines have acquired the telegraphic style where verbs can be substituted by nouns creating a noun chain. It is common for newspapers to make the headline very informative. Noun strings can replace long sentences, e.g. The stage was invaded by those who wanted to make a selfie with the actor in the middle of the concert. The headline (1) producer has used only the key words for the headline. The need for decoding this type of headlines triggers different interpretations.

\section{(2) Religious studies shake-up to 'prepare pupils for life in modern Britain'}

Because of the polysemy, nouns and verbs can be misunderstood as in the example (2). It may be interpreted as 'the shake-up of religious studies' as well as 'studies shake up students to get ready for life in modern Britain'.

It is worth mentioning that non-finite verb forms including participles and infinitive constructions also establish a platform for ambiguity. The reason for that is the omission of auxiliaries that help grasp the meaning. For example, the students may think that the ending "ed" refers either to the adjective or the past 
simple regular verbs or a noun with "ing" signifies the present continuous tense (Reah 2003: 13).

\section{(3) Juliet Stevenson on the rewards of playing Mother Teresa}

In the example (3) playing may serve as an attributive modifier 'playing Mother Teresa', that is, Mother Teresa who is playing. In another interpretation, playing acts as an object, i.e. playing (Mother Teresa) got rewards.

4) Government push to clean up Britain and make dropping litter 'as socially unacceptable as drink driving'

In the following headline 'dropping litter' may be interpreted dually, as an act of dropping or throwing litter, and 'litter that is dropping or falling down'.

The headline looking as if it were a compound or a complex sentence appears to be a chain of reference. To understand the meaning of the chain, profound background knowledge of the language is needed.

(5) Norman Baker reveals drugs proposals Theresa May stripped from report

(6) David Cameron on London Grammar: Music world cringes as the PM ruins another band's credibility to be a fan

(7) Letting people get away with anything. Is this the fine art of leadership, David Cameron-style?

(8) Ukip MEP Roger Helmer: People should be able to dislike homosexuality like they do different types of tea

(9) Jim Murphy promises to unify Scottish Labour as poll predicts Holyrood meltdown

(10) That which does not kill Ed Miliband probably won't make him stronger

Producing long headlines with complex structures seem informative to a large extent, which supposedly attract readers to the news item. However, these structures are loaded with prior knowledge that the reader needs to understand the information properly. As in headline (5) the author includes personal names that are supposed to be well-known to the reader and the prior knowledge that there have been drug proposals and Teresa May has violated the rules of reporting on that incident. In addition, the structure lacks conjunctions between the two clauses. Headline (6) is heavily loaded by a range of syntactical forms, such as the present simple tense in cringes, ruins, a noun-string chain in another band's credibility, a prepositional non-finite phrase by claiming, and the infinitive construction to be a fan. Headline (7) has a combination of two different sentence types, an elliptical statement and an interrogative. Moreover, 
the statement is elliptical lacking either a subject or a predicate depending on the individual interpretation. Headlines (8) and (9) employ conjunctions as, like to join two clauses, but what is misleading is the propositional content of the clauses, which requires background knowledge to understand the gist of the article. The sentence (10) is overloaded by the use of the modifier that acting as the subject and which that explains what is meant by that. Additionally, the headline has an ideological stance of the text producer by disclosing the actual topic of the article. The weakness and a high degree of ambiguity in such sentences are achieved by the amount of insufficient information passed on to the reader. The author may not know the information or does not want to tell, in such a way attracting the mass audience to read the article.

One of the most frequently used grammar tense forms is the present simple. Apart from the newspaper context, this verbal form is used extensively in English syntactic structures. The most common practical application of the tense form is expressing regular habitual actions, state actions in present, planned future actions, actions in dramatic narrative, and as a verbal form in time clauses. Such extensive use of the tense form provokes a good deal of ambiguity in understanding.

\section{(11) City Link collapse: union meets administrators in effort to save jobs}

The reader may assume that the union has already met administartors, where the verb meets expresses a completed action. Similarly, it may also imply a future action.

\section{(12) NHS crisis grows as young Britons turn their backs on family doctors}

The headline may express the continuous process of growing of NHS crisis taking place at the time of reading the article.

\section{(13) Devon drops plan to ban smokers and the obese from routine operations}

The implied meaning of drops may signify the intention to stop the plan of prohibiting smokers perform routine operations. It may also mean that the decision has already been made.

\section{(14) Labour tells businesses to act fast to make case for the UK in Europe}

Here, the sentence (14) has a pragmatic load. The headline author intends to express the Labour party's recommendation for enterprises to act faster in the future or suggests that the party habitually reminds them to act faster. 
Modality is also used extensively in the headlines, which emphasises the relationship of the text producer and the addressees. The author may express the attitude towards a certain situation, issue, or event. Modal verbs have a wide range of meanings causing a lot of misinterpretations. They often occur when the target language does not have relevant equivalent phrases or word combinations. The following headlines contain modal verbs, like need, would, should, must, won't.

\section{(15) Local courts need to be run by local people}

(16) Referendum would turn UK's presidency of EU into a 'farce'

(17) How Labour would reform the Work Capability Assessment

(18) British Bill of Rights 'would protect free press'

(19) Nigel Farage: David Moyes should join Ukip

(20) David Cameron won't rule out Ukip deal in hung Parliament

(21) Soaking the rich won't cut poverty or inequality

(22) The Conservatives must reconnect with voters' aspirations

(23) Britain must be ready to 'walk out' on European Union, Matt Hancock says

Generally, the modal need expresses physical necessity. In the headline (15), it is not quite clear who exactly defines this necessity, either local courts themselves seek for assistance from local people or the local people insist on taking over the duties of local courts.

The extensive number of meanings of the modal would mislead in many headlines. The modal would is often used in conditional sentences expressing unreal past actions, habitual actions in the past, or annoying actions. Suppose that headlines (16) and (18) are parts of conditional sentences, and then the sentences lack the propositional content of the other part of the headline. Thus, the context is important to provide the most appropriate interpretation of the modality form and the content of a headline.

The headlines (22) and (23) contain the modal must that expresses a strong obligation or a high degree of certainty. From the context of the headline (8) the reader may suppose that the intended meaning of must in this sentence is a strong obligation or recommendation. However, the use of must in combination with be in (23) turns the message into the expression of certainty that may imply Britain is ready to 'walk out'. Similarly, the negation of the modal verb will, such as won't may express the prediction of an event that will or will not happen. Another possible interpretation may imply volition, as in (20) the text producer could have expressed David Cameron's determined refusal to rule out Ukip. Consequently, it would change the entire meaning of the headline and the main idea of the article that this headline represents. 


\section{Conclusion}

Summing it all up, since the language itself is a changeable notion, it is of utmost importance for young language specialists to master the latest tendencies in the language development. Apart from extensively employed syntactic structures, the newspaper text with its 'real' language contains plenty of new coinages, neologisms, foreignisms, morphological transformations, and culturebound vocabulary. Nowadays, having developed the linguistic system of its own the language of headlines has become confusing and not reader-friendly to a great extent. To become skilful translators and understand all the nuances of the language, students need additional training in acquiring the features of the headlinese.

\section{References}

Bagnall N. (1993). Newspaper Language. Oxford: Focal Press.

Bowels, D.A. and Borden, D.L. (1997). Creative Writing Editing for Print Media.London: Wadsworth Publishing Company.

Quirk, R., et al. (1991). A Comprehensive Grammar of the English Language. Oxford: Longman Group Ltd.

Reah, D. (2003). The Language of Newspapers. $2^{\text {nd }}$ ed. London and New York: Routledge.

Smith, R. B., Michalak, B. (1978). How to Read Your Newspaper. New York, Chicago and London: Harcourt Brace Jovanovich, Inc. 